\title{
COMPARATIVE STUDY OF FOUR HEMATOLOGY ANALYZERS
}

Deepshikha Dave1 ${ }^{1}$ Amrish N. Pandya²

\section{HOW TO CITE THIS ARTICLE:}

Deepshikha Dave, Amrish N. Pandya. "Comparative Study of four Hematology Analyzers". Journal of Evolution of Medical and Dental Sciences 2014; Vol. 3, Issue 12, March 24; Page: 3107-3113,

DOI: $10.14260 /$ jemds/2014/2251

ABSTRACT: In today's world of automation it's important to know whether all automated hematology analyzers if run with appropriate control results, give the same result or not. This study was carried out using ABX-Micros-60, Sysmex-KX-21, Advia-120 and Erma-PCE-210. Same sample including EQAP sample was run within two hours on all instruments. Results were noted and modified -ANOVA test was used to check whether all machines were similar in overall results or not. Seven parameters were assessed. For RBC-counts, WBC-counts and platelet counts Sysmex-KX-21 and Advia-120 were similar. For RBC-counts and WBC-counts all analyzers were similar. For platelet counts except Sysmex-KX-21 and Advia-120 all differed. For hemoglobin all differed. For MCV and Lymphocyte percentage except Sysmex-KX-21 and Erma-PCE-210 all differed.

KEYWORDS: ABX-Micros-60, Sysmex-KX-21, Advia-120, Erma-PCE-210, EQAP, hemoglobin, RBC, WBC, platelet, counts.

AIMS: The concept of automation in hematology in the form of electronic cell counters is gaining wide acceptance in India. Within the past two decades, there has been an influx of automated and semi-automated blood cell analyzers in hematology laboratories. Pathologists are increasingly becoming aware of the benefits of automated cell counters as regards their precision and accuracy along with the shorter sample turnover time as compared to manual methods. Pathologists, who opt for automated cell counters, recognizing their potential, should use the instruments as per standard recommendations of the companies, by maintaining regular checks on their instruments.

However, quite a few pathologists are satisfied with whatever results their counter gives them without realizing the importance of regular checks and quality control exercises for obtaining reliable results. A number of analyzers of different makes are available in the market today. Most of these counters are pre-calibrated by the company in certain modes; however, there are certain parameters which can be calibrated by the individual pathologist. As a result there is bound to be some degree of variability in the results obtained from each counter.

Yet no counter can be called good or bad. The "goodness" or "badness" of a counter is largely created by the operator. Depending on his keen observation and recognition that his counter is going wrong in a particular aspect (which can then be recalibrated), the operator can maintain his counter in good shape. Here is where a need for Inter-laboratory Quality Control programs (External Quality Assessment) is felt necessary. Same blood sample(s) may be run at different laboratories and the variability in the results obtained may be studied and gross variations may then be analyzed and corrected accordingly, on the basis of standard protocols.

A rather easy and fairly reliable method of carrying out quality control exercises is with the help of commercially available cell controls. The cell controls are run on instruments and if the results obtained do not fall within the expected range, the cell counter may be recalibrated.

The Complete Blood Count (CBC) is the most frequently performed investigation by a laboratory, be it private or institutional, clinical or research-oriented. In effect, up to $70 \%$ of the 


\section{ORIGINAL ARTICLE}

workload of a laboratory is comprised of CBCs prescribed by general practitioners, internists, hematologists and other super specialists. The OPD laboratory as well as indoor hematology laboratory including sickle cell laboratory at New Civil Hospital, Surat is well equipped with the facility of automated cell counters.

Most of the counters are of different makes. After having seen a number of CBC reports of individual patients and an occasional CBC report of the same patient from two laboratories, a definite need was felt to find out the reliability and comparability of cell counters being used at different laboratories in new civil hospital Surat. Blood counts now being the basic investigations and routine procedure before any further workup of patient should be dealt with caution as analyzers are routinely being used for them. Fully automated instruments require only an appropriate amount of blood sample that is presented to the instrument. They are multichannel instruments, i.e. they usually measure 8-20 variables including some new parameters which do not have any equivalent in manual techniques ${ }^{1}$.

Automation in hematology has gained wide acceptance in India. There are various makes of automated hematology analyzers available. Whether all of these are similar in their results or not, this study is an attempt to assess the same with available set of analyzers. Prerequisite before judging these counters was that they were running within control by their respective company manufactured control samples. As well as all of them were calibrated and two out of four were under EQAP program assessment.

MATERIAL AND METHODS: This study was conducted at Pathology department Govt. medical college, Surat. Random selection by selecting every fourth patient's sample for running on analyzer (whether male or female) was done. Four automated hematology analyzers of different make were used. Sample was run within two hours of collection. Hematology analyzers were ABX-Micros-60, Sysmex-KX-21, Advia-120 and Erma-PCE-210. Total ten samples of EQAP and 62 patient's sample were run on all the counters. On Advia-120 only one EQAP sample was run as it was introduced late in the study.

All machines were under strict quality check and were calibrated. EQAP results of the two machines i.e. sysmex-KX-21 and ABX-Micros-60 were satisfactory throughout the test. Since these two machines were under NABL scope throughout the test one of these two machines i.e. sysmex-KX21 was selected for the inter-instrument comparison. These two machines were having good linearity, no carry over and good precision. Range for linearity was higher for sysmex-KX-21 for all counts hence it was taken as standard for inter-instrument comparison.

This study included one five part analyzer Advia-120 so parameters considered for comparison were hemoglobin, RBC counts, WBC counts, platelet counts, hematocrit, MCV and lymphocyte percentage. Overall assessment was to check whether all analyzers if undergoing strict quality check, give similar results (statistically) or they differ.

ETHICS: Samples collected for checking were original samples derived from the patients. EQAP samples came from the AIIMS, New Delhi.

STATISTICS: Modified-ANOVA (Analysis of Variance) was used.

DISCUSSION: All pathologists want an analyzer that gives the best result. The hematology analyzers which are under strict quality check specially when they are graded as satisfactory on EQAP 
assessment need not necessary give similar results when tested with a different set of quantitative data (i.e. patient's with different clinical conditions with varied hematological results).

Most of the studies mentioned in literature have evaluated newer counters in comparison to the better known, established cell counters. Two studies which carried out a parallel evaluation of more than two counters those conducted by Jones et al (1995) ${ }^{2}$ and Bentley et al (1993) ${ }^{3}$ respectively. Recent study by Drewinko B, comparing flow cytometry based analyzers with the conventional ones showed their superiority in terms of linearity and precision ${ }^{4}$, but how much impact does it make in assessment was included in our study as one analyzer Advia120 is based on flow cytometry in our study.

Jones et al 2 compared the performance of cell counters by analyzing the coefficient of correlation. Many other workers have also evaluated counters in terms of coefficient of correlation. However, J M England (1996) ${ }^{5}$ comments that correlation coefficients should not be used to analyze data while evaluating a cell counter since they give no information about comparability. As many as $20 \%$ of the values may be found to fall out of line for a comparison which has otherwise been reported by a correlation coefficient of 1 .

In previous two studies by Bain et al on comparison between two cell counters one study showed with respect to accuracy both automated counters showed statistically significant difference from each other in differential counts ${ }^{6}$. Other study showed $58 \%$ of blood samples counted by one cell counter required a blood film examination, and other one was imprecise in results 7. One study by Devreese et al showed two analyzers to be correlating good for hemoglobin, WBC counts, hematocrit and platelet counts ${ }^{8}$. And similar was the finding of the study conducted by Sheridan et al on two different make analyzers 9 .

In the west, it is mandatory for laboratories to participate in the external quality assessment programmes e.g. in the United Kingdom, for a laboratory to get accreditation it has to participate in the UK NEQAS (H) (United Kingdom National Quality Assessment for Hematology) ${ }^{5}$. Similarly in the USA as per Clinical Laboratory Amendment 1988 (CLIA, 1988) ${ }^{5}$ laboratories have to participate in external quality assessment programmes such as those being run by the College of American Pathologists. In India, this is done by All India Institute of Medical Sciences (AIIMS) through program called EQAP 10.

As parallel part of study the EQAP samples were run on ABX-Micros-60, Sysmex-KX-21 and Erma-PCE-210. As is evident from tables all counters reported different mean values for each variable in first phase of the study which dealt with random patient samples. The variability of the calculated means of all variables was analyzed by deriving the coefficient of variation (CV). A difference in the CV was observed but Sysmex-KX-21 and Advia-120 showed nearly same CV for all seven parameters (Table 1, 3, 5, 7, 9, 11, 13). The lowest and highest CV was for MCV (mean corpuscular volume) (Table $13,14)$ and total leukocyte counts (Table 5,6$)$ respectively.

Since machines were calibrated and EQAP results applied to Sysmex-KX-21 and ABX-Micros60 (both under EQAP program separately) and stamped as satisfactory by results of EQAP, the difference that come as a result of patients samples run on them indicated inherent system capacity (difference).

CONCLUSION: As per statistical conclusion for total WBC \& RBC counts (Table 5, 6, 7, 8) all the counters showed nearly same values and they don't differ. For platelet counts (Table 1, 2) SysmexKX-21 and Advia-120 are similar rest all differ. For hematocrit (Table 9, 10) Sysmex-KX-21, Advia- 
120, PCE-210 are same but ABX-Micros-60 differ. For MCV (Table 13,14) and lymphocyte percentage (Table 11, 12) Sysmex-KX-21 and PCE-210 are same, rest all differ. For Hemoglobin (Table 3, 4) all counters are different.

\section{REFERENCES:}

1. Bain BJ Bates I. Basic haematological techniques. Lewis SM, Bain BJ Bates I(ed). Dacie and Lewis Practical Hematology, 18th Edition. London: Churchill Livingstone; 2001; 19-47.

2. Jones RG, Faust AM, Matthews RA. Quality team approaches in evaluating three automated haematology analyzers with five part differential capacity. Am J Clin Pathol 1995; 103:159-66.

3. Bentley SA, Johnson A, Bishop CA. A parallel evolution of four automated haematology analyzers. Am J Clin Pathol 1993; 100:626-32.

4. Drewinko B. Eight-parameter automated hematology analyzer. Comparison of two flow cytometric systems. Am J Clin Pathol 1982; 78:738.

5. England JM. Automated blood cell counters. In Hoffbrand AV, Brener MK(ed). Recent Advances in Hematology, Number eight. New York: Churchill Livingstone; 1996; 159-89.

6. Bain BJ, Neill PJ, Scott D, Scott TJ, Innis MD. Automated differential leucocyte counters: an evaluation of the Hemalog D and a comparison with the Hematrak. I. Principles of operation; reproducibility and accuracy on normal blood samples. Pathology. 1980 Jan; 12(1):101-9.

7. Bain BJ, Neill PJ, Scott D, Scott TJ, Innis MD. Automated differential leucocyte counters: an evaluation of the Hemalog D and a comparison with the Hematrak. II. Evaluation of performance on routine blood samples from hospital patients. Pathology. 1980 Jan; 12 (1):83100.

8. Devreese K, De Logi E, Francart C, Heyndrickx B, Philippe J, Leroux-Roels G. Evaluation of the automated hematology analyzer Sysmex NE-8000. Eur J Clin Chem Clin Biochem. 1991 May; 29 (5):339-45.

9. Sheridan BL, Lollo M, Howe S, Bergeron N. Evaluation of the Roche Cobas Argos 5 Diff Automated Hematology analyzer with comparison to a Coulter STKS. Clin Lab Hem (2)1994; Jun: 117-30.

10. Renu S, Gayatri G, SK Sood. Quality Assessment of Automated Electronic Cell Counters. In Renu S(ed). Recent Advances in Hematology-2, 2nd edition. New Delhi: Arya; 2000; 286-96.

\begin{tabular}{|l|c|l|c|}
\hline Factor & Mean & Std. error & 95\% CL \\
\hline SYS* & 251.2097 & 17.1589 & 216.8983 to 285.5211 \\
\hline PCE $\dagger$ & 221.8710 & 12.3514 & 197.1729 to 246.5691 \\
\hline M_60 $\neq$ & 265.3387 & 16.4263 & 232.4922 to 298.1852 \\
\hline ADVIA§ & 252.9194 & 16.9815 & 218.9628 to 286.8759 \\
\hline
\end{tabular}

Table 1: For platelet counts within subject factors

* Sysmex-KX-21 † Erma-PCE-210 ‡ ABX-Micros-60 § Advia-120

\begin{tabular}{|c|c|c|c|c|c|c|}
\hline Factor & Vs & Factor 2 & Mean difference & Std. error & Pa & 95\% CLa \\
\hline SYS & & PCE & 29.339 & 6.907 & 0.0004 & 10.504 to 48.174 \\
\hline & & M_60 & -14.129 & 4.372 & 0.0119 & -26.050 to -2.202 \\
\hline & & ADVIA & -1.710 & 1.281 & 1.0000 & -5.203 to 1.783 \\
\hline
\end{tabular}

Table 2: For platelet counts Pairwise comparison 
ORIGINAL ARTICLE

\begin{tabular}{|c|c|c|c|}
\hline Factor & mean & Std. error & 95\% CL \\
\hline SYS & 12.0968 & 0.2852 & 11.5266 to 12.6670 \\
\hline PCE & 11.6613 & 0.2839 & 11.0935 to 12.2291 \\
\hline M_60 & 11.3532 & 0.3056 & 10.7422 to 11.9642 \\
\hline ADVIA & 11.9484 & 0.2845 & 11.3795 to 12.5172 \\
\hline
\end{tabular}

Table 3: For hemoglobin within subject factors

\begin{tabular}{|c|c|c|c|c|c|c|}
\hline Factor & Vs & Factor 2 & Mean difference & Std. error & Pa & 95\% CLa \\
\hline SYS & & PCE & 0.435 & 0.0423 & $<0.0001$ & 0.320 to 0.551 \\
\hline & & M_60 & 0.744 & 0.114 & $<0.0001$ & 0.432 to 1.055 \\
\hline & & ADVIA & 0.148 & 0.0323 & 0.0001 & 0.0604 to 0.236 \\
\hline
\end{tabular}

Table 4: For hemoglobin Pairwise comparison

\begin{tabular}{|l|l|l|l|}
\hline Factor & mean & Std. error & $\mathbf{9 5 \%}$ CL \\
\hline SYS & 7.1597 & 0.5618 & 6.0363 to 8.2831 \\
\hline PCE & 7.2871 & 0.5791 & 6.1290 to 8.4451 \\
\hline M_60 & 7.4097 & 0.5363 & 6.3372 to 8.4822 \\
\hline ADVIA & 7.2081 & 0.5688 & 6.0707 to 8.3454 \\
\hline
\end{tabular}

Table 5: For WBC counts within subject factors

\begin{tabular}{|c|c|c|c|c|c|c|}
\hline Factor & Vs & Factor 2 & Mean difference & Std. error & Pa & 95\% CLa \\
\hline SYS & & PCE & -0.127 & 0.0479 & 0.0599 & -0.258 to 0.00325 \\
\hline & & M_60 & -0.250 & 0.125 & 0.2975 & -0.590 to 0.0903 \\
\hline & & ADVIA & -0.0484 & 0.0311 & 0.7485 & -0.133 to 0.364 \\
\hline
\end{tabular}

Table 6: For WBC counts Pairwise comparison

\begin{tabular}{|c|c|c|c|}
\hline Factor & mean & Std. error & $\mathbf{9 5 \%}$ CL \\
\hline SYS & 4.2132 & 0.1028 & 4.0077 to 4.4188 \\
\hline PCE & 4.1885 & 0.09343 & 4.0017 to 4.3754 \\
\hline M_60 & 4.1297 & 0.1053 & 4.9190 to 4.3403 \\
\hline ADVIA & 4.2027 & 0.09998 & 4.0028 to 4.4027 \\
\hline
\end{tabular}

Table 7: For RBC counts within subject factors

\begin{tabular}{|c|c|c|c|c|c|c|}
\hline Factor & Vs & Factor 2 & Mean difference & Std. error & Pa & 95\% CLa \\
\hline SYS & & PCE & 0.0247 & 0.0160 & 0.7754 & -0.0191 to 0.0684 \\
\hline & & M_60 & 0.0835 & 0.0453 & 0.4200 & -0.0400 to 0.207 \\
\hline & & ADVIA & 0.0105 & 0.00949 & 1.0000 & -0.0154 to 0.0364 \\
\hline \multicolumn{6}{|c}{ Table 8: For RBC counts Pairwise comparison } \\
\hline
\end{tabular}


ORIGINAL ARTICLE

\begin{tabular}{|c|c|c|c|}
\hline Factor & mean & Std. error & 95\% CL \\
\hline SYS & 36.7097 & 0.7795 & 35.1510 to 38.2684 \\
\hline PCE & 36.3258 & 0.7610 & 34.8042 to 37.8474 \\
\hline M_60 & 34.7677 & 0.8438 & 33.0805 to 36.4550 \\
\hline ADVIA & 36.6613 & 0.7687 & 35.1241 to 38.1985 \\
\hline
\end{tabular}

Table 9: For hematocrit within subject factors

\begin{tabular}{|c|c|c|c|c|c|c|}
\hline Factor & Vs & Factor 2 & Mean difference & Std. error & Pa & 95\% CLa \\
\hline SYS & & PCE & 0.384 & 0.242 & 0.7047 & -0.275 to 1.043 \\
\hline & & M_60 & 1.942 & 0.312 & $<0.0001$ & 1.091 to 2.793 \\
\hline & & ADVIA & 0.0484 & 0.0593 & 1.0000 & -0.113 to 0.210 \\
\hline
\end{tabular}

Table 10: For hematocrit Pairwise comparison

\begin{tabular}{|c|c|c|c|}
\hline Factor & mean & Std. error & $\mathbf{9 5 \%}$ CL \\
\hline SYS & 31.9500 & 1.7130 & 28.5247 to 35.3753 \\
\hline PCE & 34.9710 & 1.9745 & 31.0227 to 38.9192 \\
\hline M_60 & 36.4839 & 1.7616 & 32.9613 to 40.0064 \\
\hline ADVIA & 32.7194 & 1.7165 & 29.2871 to 36.1516 \\
\hline
\end{tabular}

Table 11: For lymphocyte percentage within subject factors

\begin{tabular}{|c|c|c|c|c|c|c|}
\hline Factor & Vs & Factor 2 & Mean difference & Std. error & Pa & 95\% CLa \\
\hline SYS & & PCE & -3.021 & 1.351 & 0.1740 & -6.705 to 0.663 \\
\hline & & M_60 & -4.534 & 0.720 & $<0.0001$ & -6.498 to -2.569 \\
\hline & & ADVIA & -0.769 & 0.149 & $<0.0001$ & -1.175 to -0.364 \\
\hline
\end{tabular}

Table 12: For lymphocyte percentage Pairwise comparison

\begin{tabular}{|c|c|c|c|}
\hline Factor & mean & Std. error & $\mathbf{9 5 \%} \mathbf{C L}$ \\
\hline SYS & 88.2290 & 1.6376 & 84.9545 to 91.5035 \\
\hline PCE & 87.4371 & 1.6773 & 84.0832 to 90.7910 \\
\hline M_60 & 85.4677 & 1.6433 & 82.1817 to 88.7538 \\
\hline ADVIA & 87.7742 & 1.6359 & 84.5031 to 91.0453 \\
\hline
\end{tabular}

Table 13: For MCV within subject factors

\begin{tabular}{|c|c|c|c|c|c|c|}
\hline Factor & Vs & Factor 2 & Mean difference & Std. error & Pa & 95\% CLa \\
\hline SYS & & PCE & 0.792 & 0.397 & 0.3028 & -0.290 to 1.874 \\
\hline & & M_60 & 2.761 & 0.595 & 0.0001 & 1.140 to 4.383 \\
\hline & & ADVIA & 0.455 & 0.0367 & $<0.0001$ & 0.355 to 0.555 \\
\hline
\end{tabular}

Table 14: For MCV Pairwise comparison 


\section{ORIGINAL ARTICLE}

\section{AUTHORS:}

1. Deepshikha Dave

2. Amrish N. Pandya

\section{PARTICULARS OF CONTRIBUTORS:}

1. Tutor, Department of Pathology, Government Medical College Surat, Gurjarat.

2. Professor and Head, Department of Pathology, IHBT, Government Medical College, Surat, Gujarat.

\section{NAME ADDRESS EMAIL ID OF THE} CORRESPONDING AUTHOR:

Dr. Deepshikha Dave,

F2, Payal Flats,

Opposite Bhulka Bhavan School, Adajan, Surat - 395009, Gujarat.

E-mail: drdeepshikhapdave@gmail.com

Date of Submission: 16/02/2014. Date of Peer Review: 17/02/2014. Date of Acceptance: 01/03/2014.

Date of Publishing: 20/03/2014. 